\title{
Cuestionamientos a la Geografía a partir del Cruising entre Hombres en Bogotá
}

\section{Questioning Geography from Cruising between Men in Bogotá}

\author{
Fernando Ramírez Arcos \\ Universidad Nacional de Colombia \\ saqqlas@gmail.com
}

\section{Resumen}

O El presente artículo tiene como fin criticar la marginalidad del sexo como tema propio de la geografía. Propongo cuatro cuestionamientos al respecto: realzar su condición espacial, discutir la particularidad de los lugares y su producción de significados, poner en tela de juicio los ordenamientos espaciales urbanos y la díada público/privado, y debatir sobre las políticas de legitimación y autoridad en la producción de conocimiento geográfico. El telón de fondo es mi etnografía sobre lugares de cruising entre hombres en la ciudad de Bogotá, punto de partida que me permite abordar el silenciamiento del carácter espacial del sexo y la validez de su análisis socio cultural. Planteo, igualmente, cómo la investigación de temas sobre sexo implica repensar la posición del geógrafo en la academia y en el trabajo de campo.

Palabras clave: cruising; sexo; lugar; público/privado; producción de conocimiento.

\begin{abstract}
The main objective of this article is to criticize the marginal position of sex as a proper topic for geography. I propose four questionings, as follows: to foreground its spatial condition; to discuss the particularity of the places and their production of meanings; to bring into question the urban spatial orders and the public/private dyad; and to debate authority and legitimate politics in the production of geographical knowledge. The background is my ethnographic studies about cruising between men in Bogotá, a starting point that allows me to tackle the silencing of the spatial character of sex and the validity of its socio-cultural analysis. Equally, I pose the question of how to research on sex topics implies to rethink the position of the geographer in the academy and in the fieldwork.
\end{abstract}

Keywords: cruising; sex; place; public/private; production of knowledge. 


\section{Introducción}

El presente artículo tiene como fin cuestionar la marginalidad del sexo como tema propio de la geografía. Aunque parto de mi experiencia en Bogotá, soy ambicioso al proponer cuatro críticas al respecto a la disciplina, que bien podrían tener eco en los estudios geográficos de otros países en América Latina. El sexo es espacial y no puede reducirse su estudio a una mera cuestión de ubicación en un mapa de los lugares de cruising entre hombres, de los bares de strip tease, de los circuitos de prostitución en las calles, de los clubes de swingers o de otras prácticas similares. Tampoco es posible citar la intimidad como valor inmanente de las actividades eróticas para no analizarlo, ya que, en la práctica, esa enunciación performativa trae consigo veladas formas de violencia hacia sus practicantes. Con el silenciamiento del sexo como espacio válido y central del análisis geográfico y socio-cultural se promueven múltiples formas de coerción y regulación que ocultan cómo su ejercicio produce espacios y cuerpos, construye ciudades, transforma paisajes, delinea subjetividades (como la de investigador), llena de sentido los lugares, favorece la creación de sexualidades alternativas y confronta el gobierno de las poblaciones.

Para apoyar mis argumentos traigo a colación mi trabajo de investigación sobre cruising entre hombres en Bogotá, en el marco de un postgrado en estudios culturales. Como cruising entiendo la búsqueda consciente de relaciones sexuales efímeras, anónimas y casuales $^{1}$ con personas en ambientes públicos o en espacios privatizados ${ }^{2}$ diseñados para estos fines. Es un anglicismo popularizado en la ciudad que, en principio, abarca un sentido más amplio que el de sexo (en) público, al abordar todas las prácticas incluidas en el acto de buscar otros hombres para encuentros sexuales. Su definición abarca las diferentes estrategias espaciales y tácticas corporales de los sujetos por alcanzar su objetivo, desde una mirada fugaz que varios minutos después puede llevarlos a encerrarse en algún cubículo de un baño de un centro comercial, hasta la ronda habitual por los pasillos de un sauna esperando a que el o los hombres de su gusto accedan al cuarto oscuro. Igualmente, pone especial atención en los contextos específicos en donde la actividad ocurre con mayor probabilidad, como un parque ya reconocido e identificado como lugar de encuentro con otros hombres antes que un baño de un restaurante familiar cualquiera. En este caso, el término 'sexo (en) público' es ambiguo e insuficiente para señalar las características que lo hacen posible, ya que sólo se enfocaría en el acto en sí mismo. Por último, y más importante, es el término privilegiado en Bogotá por algunos de sus practicantes para identificar actos públicos sexuales entre hombres, al menos en internet. Es común encontrarlos hablando al respecto en salas de chat o grupos de redes sociales, identificando sus experiencias bajo ese concepto en los últimos años.

En libros destacados sobre el tema, cruising es casi usado como sinónimo de sexo (en) público, así los títulos prefieran este último. Pat Califia (1994) usa cruising como sustantivo y verbo, y para darles identidad a sus practicantes (cruisers), pero no realiza distinción alguna con public sex. Lo mismo sucede con algunos artículos del libro Public Sex / Gay Space, editado por el antropólogo estadounidense William L. Leap (1999). Por ejemplo, Hollister (1999) lo equipara con área, sitio, actividad y repertorio de técnicas, y lo usa como verbo (to cruise) para connotar la acción de buscar. Leap (1999) arguye en la introducción del libro que otro artículo usa el vocablo como constructor de "una compleja geografía sexual" (LEAP, 1999, p. 8), junto a hustling y scoring, palabras populares estadounidenses sobre búsqueda de sexo por dinero.

En mi opinión, la escasa frecuencia del término cruising en los títulos de textos académicos se debe a la tenacidad de los y las autoras por problematizar y criticar el binomio público/privado, quienes actúan como ficciones heteronormativas que establecen el qué y el cómo del sexo. Un ejemplo reciente lo protagoniza Phil Hubbard (2012), quien en el comienzo del capítulo titulado Public sex argumenta que "los intereses del estado sobre la sexualidad frecuentemente se extienden al dormitorio privado, convirtiendo la 'moralidad privada' en un asunto de 'preocupación pública”" (HUBBARD, 2012, p. 91)3. Más adelante, continúa su disertación sobre el carácter ambiguo del sexo respecto a lo público y lo privado, y cómo algunas veces el derecho a la privacidad, que no contradice necesariamente lo público del $\mathrm{sexo}^{4}$, puede ser determinante para algunas personas para evitar ataques físicos $\mathrm{y} / \mathrm{o}$ verbales. Hubbard es enfático en describir la tensión recurrente de los hombres frente a su opción de tener sexo consensuado en lugares como parques y baños públicos, pero al tiempo fuera de la vista de posibles curiosos y entrometidos. Señalamiento que comparten Califia y Leap.

Mi opción final por cruising en vez de sexo (en) público se debe, ante todo, a su popularidad en la ciudad. En él incluyo los establecimientos comerciales que brindan comodidad, 'seguridad' y 'libertad' a sus usuarios para conseguir sexo, como cualquier otra zona de encuentro casual homoerótico al aire libre o público de 'libre' entrada, como baños de centros comerciales, campus universitarios, transporte urbano, entre otros. No obstante, en mi investigación sólo escogí tres lugares privatizados: un 'video', un sauna y

Fernando Ramírez Arcos 
un club de sexo, ubicados en la zona gay ${ }^{5}$ más popular de Bogotá, la localidad de Chapinero. Además, mi etnografía dialoga con algunos textos geográficos que comentan sobre el sexo de forma directa o tangencial. Principalmente, recojo los principales señalamientos de algunos artículos críticos sobre la forma de 'hacer geografía', como [screw]ING GEOGRAPHY (censor's version) (1995) y Fucking Geography, again (2007), del geógrafo inglés David Bell. Ambos pertenecen a una amplia gama que, afortunadamente, poco a poco se está consolidando en América Latina de investigaciones sobre el espacio, el género, la sexualidad, y su realidad fundante en torno a la homofobia, las violencias a personas transgénero y travesti, los actos públicos de movimientos sociales LGBTI, las luchas por igualdad en derechos civiles, la abyección y otredad de los cuerpos no normativos, entre otros tópicos. Artículos que inspiran a continuar investigando desde posiciones marginalizadas y críticas en la geografía, que evitan caer en postulados inflexibles sobre el proceder de la disciplina, que se cuestionan por nuevas formas de acercarse al campo, que subvierten las miradas masculinistas, patriarcales y heteronormativas (al igual que homonormativas) que silencian y borran las experiencias diversas de personas no convencionales en torno a sus identidades.

Por tanto, el presente artículo es, antes que todo, una contribución más para joder, fornicar, follar con/a la geografía. David Bell (2007) describe cuatro sentidos del verbo to fuck en la década de los 90, pero que aún hoy siguen manteniendo vigencia: primero, como provocación para repensar los límites epistemológicos de la disciplina en una época marcada, por un lado, por la rápida difusión del VIH-SIDA y las lentas respuestas de los gobiernos mundiales a tal situación, y por el otro, por las luchas activistas del grupo ACT UP y la creciente recepción en la academia de la teoría queer. Segundo, para considerar el sexo como tema posible de investigación. Tercero, como un señalamiento de protesta a la Asociación de Geógrafos Americanos y su censura al texto presentado en la reunión anual de 1994 en San Francisco, cuyo título contenía la palabra fucking. Texto que sería publicado un año después en Society and Space con el cambio pertinente. Bell debió negociar y ceder en ambos casos, primero, usando screwing en vez de fucking (pero añadiéndole un tono sarcástico con la inclusión de la frase censor's version), y segundo, eliminando de la publicación las imágenes que usó en su presentación, entre ellas, un cómic de Tom of Finland en que uno de sus acostumbrados hombres hipermasculinizados e hipersexualizados se 'coge' al planeta. Cuarto y último, para follarse a la geografía, para tener sexo con el espacio. Aunque reconozco que las definiciones expuestas por el autor pueden ser muy precisas y contextuales, ¿quién no se siente interpelado por los límites disciplinarios de algunos profesores en la disciplina que marcan qué es geografía y qué no lo es? ¿Qué hay de las luchas contemporáneas activistas, la recepción de nuevas teorías sobre el género y la sexualidad, y la legitimidad al hablar del sexo como tópico de investigación? ¿Cuántos espacios en la academia aún en la actualidad omiten temas 'sensibles' a entes reguladores que tienen objeciones con los títulos, con algunas palabras utilizadas o con el contenido formal del texto?

Por esas y otras preguntas, adhiero a los sentidos propuestos por Bell porque pienso que aún hoy es muy difícil hablar de estos temas en la geografía (y en otras disciplinas de las ciencias sociales) en que la censura está a la orden del día; porque temas de investigación similares siguen siendo objeto de discriminación por parte de docentes que piensan que sólo le atañen a un reducido grupo de personas marginalizadas, y porque todavía encontramos múltiples casos de violencia contra portadores de VIH-SIDA, con políticas mudas y exangües a las realidades sociales de los principales afectados. Además, es imposible obviar la creciente acogida de los estudios queer en algunos países de América Latina. Joder a la geografía, pues, es revolcarla y sacarla de su burbuja de seguridad que le brinda la tecnificación de la cartografía, la convencional planificación urbana y regional o los estudios geográficos sin ningún análisis social $\mathrm{y}$ cultural de los espacios que investigan.

El artículo se divide en tres secciones. La primera parte expone qué entiendo por homonormatividad y cuál es su articulación con el cruising 'gay'. Uso ese concepto como telón de fondo de lo público y/o privado del sexo en el espacio. La segunda parte describe los tres lugares privatizados que investigué, donde los hombres buscan sexo casual, esporádico y anónimo con otros hombres. Adjetivos que están lejos de ser totalizantes, ya que también son espacios donde se interrelacionan, conversan, crean redes de amistad e intercambian información personal para futuros encuentros. Mi propósito en esta sección es evidenciar el cruising bogotano como contextual, que las dinámicas de los lugares varían, que el control interno que ejercen los dueños para regular las conductas de sus clientes puede transgredirse, que la casualidad y anonimato también producen conocimiento y formas de follarse y estar en el mundo. La tercera parte menciona los cuestionamientos sobre el qué y el cómo de la investigación en la geografía cuando el sexo es el centro de estudio. Tales críticas están acompañadas de algunos ejemplos traídos del campo y de diversos textos académicos. Al final, visito de nuevo a David

Fernando Ramírez Arcos 
Bell y sus sugerentes postulaciones.

\section{Homonormatividad en Chapinero}

Bogotá tiene al menos tres importantes zonas de concentración de lugares para hombres no heterosexuales. El más reconocido y popular es Chapinero, nombre histórico dado a un conjunto de barrios céntricos de la capital colombiana, que agrupados conforman una localidad ${ }^{6}$. En él, se concentran más de 100 establecimientos comerciales gay, por lo que no es sorpresa que sea el centro de atención de las políticas públicas LGBTI de la ciudad y el espacio de representación por excelencia del hombre gay normativo: blanco/mestizo, con capacidad adquisitiva, de cierta posición social (o que al menos pretende serlo), joven, de apariencia física 'atractiva' y consumidor compulsivo de productos marcados como tal identidad sexual. Chapinero concentra la mayor atención estatal, distrital, social y comercial de la homosexualidad masculina en Bogotá.

Los lugares escogidos para mi trabajo de campo se encuentran en este espacio, en el que circulan algunas visiones de la homosexualidad masculina, pero del cual emerge como hegemónico e ideal el modelo de sujeto descrito con anterioridad. En mi opinión, las políticas públicas y los establecimientos comerciales juegan un papel fundamental en el sostenimiento de representaciones sesgadas y reduccionistas de la homosexualidad masculina que devienen normativas, al tiempo que reprochan y marginan otras visiones, algunas de ellas alternativas, radicales y transgresoras. Los lugares como bares, cafés y discotecas son la columna vertebral del sistema homonormativo que crea normas y pautas de vida bajo un intervalo específico de normalización, al tiempo que emergen como espacios genuinos y auténticos para la socialización. Lugares que se convierten en escuelas de aprendizaje: indican cómo deben vestirse los hombres, cómo moldear su cuerpo a patrones específicos de belleza, cómo relacionarse con otros hombres, cómo conseguir pareja, cómo flirtear, cómo bailar, cómo comportarse, cómo hablar, en fin, cómo performar al hombre gay.

La homonormatividad en Chapinero no da por bien visto hablar con soltura y prolijidad de los lugares de encuentros sexuales fortuitos. Ellos están marcados por la reprobación, la incomprensión, la injuria, la humillación, la burla, el asco, y son identificados como espacios a los cuales asisten solamente hombres discriminados por cuestiones de clase, edad, aspecto físico, estado de salud y malas habilidades para el flirteo. Lo cual es falso, porque a ellos también asisten hombres que pueden ser descritos como atractivos y jóvenes, de clase media/alta, seronegativos y que también asisten a los lugares más reconocidos de la localidad. Los lugares de cruising cargan con signos de perversidad y abyección heredados de discursos morales judeocristianos que aún hoy ven con ojos de pecado y reprobación las prácticas sexuales fuera de la constitución de la familia heterosexual, monogámica y reproductiva. Por tanto, no es extraño que algunos hombres que asisten a ellos prefieran la discreción y el silencio para evitar que otras personas sepan de sus visitas y hábitos. Huyen de la vergüenza, cuando ella es en realidad un efecto performativo de la distinción moral y normativa de los espacios de socialización para hombres gay, así como lo son otro tipo de emociones, como la felicidad y la alegría derivadas del baile, el alcohol y las drogas consumidas en alguna discoteca.

En realidad, el sexo como discurso puede actuar como una variable de espacialización homonormativa y moral, que distingue lo permitido de lo prohibido en el espacio público. Hubbard (2012) destaca cómo el sexo carga con signos de lo correcto/incorrecto, puro/impuro, positivo/negativo, central/periférico, ejemplarizante/pervertido, normal/anormal, decente/indecente, decoroso/obsceno, limpio/sucio, que intimidan algunos actos de la escena pública porque, supuestamente, son del entorno privado. Es decir, se privatiza aquello que debe estar alejado de lo visible, de lo reconocible en las calles, en los parques, en los centros comerciales, en las universidades. Los actos sexuales hacen parte de numerosas prácticas corporales que deben ser consignadas en la intimidad que brinda un hogar y sólo con personas de la más entera confianza. La vergüenza que una persona debe sentir por exhibir lo marcado como prohibido, hace parte de una serie de mecanismos de control y gobierno socio-espacial que impulsan el auto vigilamiento y reprueban cualquier acto que se extralimite del intervalo de aceptabilidad impuesto. Intervalo que es fluido e interpelado, pero de una fuerza performativa enorme, como nos recuerda Hubbard (2012) con sus ejemplos de los nudistas y la desaparición progresiva del amamantamiento de madres a sus hijos del espacio público, o Longhurst (2001), con las mujeres embarazadas en los espacios públicos de la ciudad de Hamilton, en Nueva Zelanda.

Los estigmas de suciedad, marginalidad e indecencia que promueve la homonormatividad favorecen una cierta desexualización del espacio gay, que limpia e higieniza los lugares de cualquier acto vergonzoso posible, so pretexto de no mantener los estereotipos sociales sobre la promiscuidad (como si efectivamente eso sucediera). El carácter impuro, amoral y aberrante del sexo (en) público designa, en

Fernando Ramírez Arcos 
parte, el lado oscuro de lo homonormativo: el lugar de luces bajas, del cuarto en penumbras, del sauna orgiástico, de las cabinas reutilizadas, del cuerpo desnudo y de la excitación constante. Pero aún en su otredad, los lugares de cruising también plantean reglas y funcionamiento controlado de las actividades sexuales de sus clientes. A continuación, hablaré un poco más de estos lugares de regulación ambigua.

\section{Cruising 'gay' bogotano}

El cruising entre hombres en Bogotá se divide en dos. Por un lado, una casa o local comercial específico por el que hay que pagar cierto precio para entrar, y cuyo interior está ordenado en cuartos oscuros, salas con proyecciones de pornografía y pequeñas cabinas para encuentros privados. Por otro lado, el sexo al aire libre y sitios no convencionales, como baños de universidades y centros comerciales, transporte público, humedales, parques y calles oscuras. Los unos y los otros manejan diferentes sensaciones de tranquilidad, seguridad, excitación, libertad y comodidad, pero la división que planteo está ante todo mediada por el pago o no a lugares que ofrecen adrede sus espacios internos para tener sexo. Con esto, no omito que los hombres que realizan actos sexuales en parques y baños públicos puedan eventualmente ser clientes de saunas. Sólo realizo esta división para poner en tela de juicio la condición performativa de lo privado y lo público, y sus estrategias ficticias veladas por el pago de un monto específico de dinero. En realidad, el cruising 'gay' bogotano bien podría dividirse por las prácticas sexuales, por las estrategias espaciales de sus practicantes, por ubicación geográfica, entre otras posibilidades.

En mi investigación decidí investigar tres lugares pertenecientes a la primera categoría. Los lugares que llamo privatizados se dividen en 'videos', saunas y clubes de sexo, de los cuales escogí uno por cada uno de ellos. Un video es un local comercial o casa remodelada, con frecuencia de dos pisos, acondicionados con salas de proyección de pornografía gay, cabinas y cuartos oscuros. El elegido mantiene un código de vestuario por días ${ }^{7}$ y se ubica en una casa de dos pisos. La primera planta se divide entre la recepción, los casilleros y una sala de televisión por cable, que además del electrodoméstico contiene un sofá y una pequeña mesa con dos grecas llenas de café y agua aromática para quien quiera servirse. A su lado, las escaleras que dan acceso al segundo piso, que se divide en tres salas de cine pornográfico gay, una sala de televisión convencional, dos baños con un espacio único compartido entre ducha, lavamanos e inodoro, seis cabinas privadas y un cuarto oscuro.
El cuarto oscuro es una habitación sin muebles y sin ninguna luz artificial encendida en su interior, pero que maneja diferentes tipos de luminosidad. Nunca está sumida en completa oscuridad, ya que los rayos de luz que se asoman a través de las cortinas que la separan del pasillo produce zonas con más o menos luminosidad; espacios de penumbra donde es posible ver quién está al lado de uno, o espacios de mayor oscuridad, donde ocurren una alta cantidad de actos sexuales. En realidad, las luces son un medio de regulación por parte de los administradores del lugar, quienes iluminan con mayor potencia el primer piso, bajan la gradación de visibilidad en los pasillos y la quitan por completo en lo que ellos a bien decidieron determinar como cuarto oscuro. La diferenciación de oscuridad o luminosidad favorece o desfavorece la intencionalidad de los sujetos en su búsqueda sexual (algunos mantienen relaciones a la vista de todos, lo cual es poco frecuente, mientras otros agarran de la mano a su acompañante y se insertan en las partes más oscuras), el tipo de acto, la cantidad de hombres involucrados, la posibilidad de acercarse o alejarse de alguien en especial, y la asistencia a algún encuentro casual.

En su etnografía sobre un cuarto oscuro en una boate de Río de Janeiro, Díaz (2007) subraya el carácter de silencio de su espacio y sus distintos ámbitos de oscuridad, que actúan como signos característicos que lo identifican como tal y que lo diferencian de otros espacios del lugar. En él, los hombres reconocen que no deben hablar de más, que sus palabras deben pronunciarse a un volumen de susurro, que ellos hacen parte de una economía de las palabras que controlan la ejecución de sus actos sexuales. El habla y la visión le dan paso al tacto como sentido guía de contacto corporal. En este espacio, lo privado y lo público entran en conflicto por la manera como los hombres buscan compañeros sexuales, en cuanto es de acceso libre dentro del video, ya que todo cliente puede ingresar y permanecer en él cuanto tiempo desee. No obstante, también es un espacio restringido por la presencia ambigua de la luz y por cuán público deseen los sujetos hacer visibles sus actos sexuales.

El otro espacio de mayor actividad sexual en el sitio es el que ocupa las cabinas privadas. Ellas son divisiones espaciales ubicadas justo al lado y al frente de una de las dos entradas posibles al cuarto oscuro. Son espacios contiguos divididos por láminas gruesas de metal que van del piso al techo, y que sirven de puerta hacia los pasillos y de pared entre ellas. Su área es alrededor de dos metros cuadrados y contienen en su interior un taburete de cuero, luz corriente de la misma intensidad o mayor que la del pasillo vecino, $\mathrm{y}$

Fernando Ramírez Arcos 
papel higiénico. Son muy populares en el video y los hombres que entran en ellas generalmente vienen del cuarto oscuro, donde el ligue ha sido efectivo y precisan de mayor privacidad, que por cierto siempre es ambigua, ya que sus láminas de metal no son precisamente a prueba de ruidos $^{8}$. La única barrera sonora que minimiza cualquier gemido, grito, palabra o sonido de carácter sexual es la música pop y electrónica, que a un alto volumen, resuena en el parlante ubicado en lo alto de la pared contigua.

La división espacial y los usos de los espacios del video - al igual que de los otros lugares comerciales de cruising- son propuestos de antemano por sus dueños y administradores. La aparición de áreas específicas para que los hombres tengan sexo implica que no es deseable (mas no es completamente prohibido) que los actos sexuales se presenten en otras no designadas. Fui testigo en algunas ocasiones de algunos de ellos en las salas con televisión pornográfica y en los pasillos. La aparición y ubicación de áreas decodificadas como 'privadas' e 'íntimas' favorecen el relacionamiento entre los hombres, facilitan que el objetivo sexual sea cumplido y que el pago de entrada al lugar sea hecho efectivo, porque el sexo explícito, comunal y a la vista de todos aún carga con significaciones de vergüenza e inmoralidad. No obstante, la posibilidad de encontrarlo más allá de las cabinas y el cuarto oscuro siempre está latente, así, poco se muestre. Lo que se presenta a la vista es un ambiente de tensión y negociación entre lo público y lo privado, en que el sexo ejerce como espectáculo posible porque es accesible y visible para los asistentes, pero factible de privatizarse (devenir privado e íntimo) en cualquier instante por deseo voluntario de las partes.

Los sujetos están continuamente jugando con los significados de lo público y lo privado. De por sí, entrar desnudo al video rompe una importante barrera social y moral: mostrar el cuerpo dispuesto para el sexo, con los genitales listos a ser usados para masturbación, felación o penetración anal. Mientras algunos hombres no los exhiben sino que los tapan con sus manos (la mayoría tiende a hacerlo), otros muestran sus penes flácidos o erectos según niveles de excitación, participación de encuentros fortuitos o por asistir a algún filme pornográfico. Algunos de ellos se masturban discretamente en solitario, ante una película o sólo si hay personas a su alrededor. El uso de los genitales son un excelente ejemplo de cómo los hombres resignifican este binomio espacial: mostrar o no mostrar, masturbarse o no masturbarse, erecto o no erecto, son performances que exponen su deseo sexual sin mayor vergüenza. Dinámicas deconstructivas que también aparecen en otros lugares privatizados de cruising.
Por ejemplo, en el sauna escogido, que es un establecimiento comercial que ofrece un sauna seco (de tipo finlandés), un sauna húmedo o a vapor (baños turcos), dos jacuzzi de diferente tamaño y una piscina, que llaman romana. Al igual que con el video, decidí mantener el nombre como es conocido en Bogotá (en género masculino), en contravía a buena parte de la literatura académica sobre cruising, en que son conocidos como bathhouses. Traducir el término al español incurriría en una especie de violencia epistemológica que sanciona el lenguaje popular, al desconocer sus propias dinámicas de identificación en la ciudad. En la realidad, 'sauna' funciona como metonimia para agrupar todos los servicios que previamente he mencionado. Cuando me refiera a uno de ellos en particular (por ejemplo, el sauna seco es conocido también como sauna) y no al establecimiento en general, haré las aclaraciones del caso.

Este establecimiento es una casa de dos pisos que se divide entre un video y el sauna. Mi trabajo de campo se enfocó en exclusiva en el último lugar, del cual destaco dos espacios concretos. El primero de ellos es el sauna seco o finlandés, que tiene doble puerta para evitar la pérdida de temperatura dada por el calentamiento de leña y de algunas hierbas, como el eucalipto, que lo impregnan de un fuerte aroma. Es contiguo al jacuzzi principal, del cual está separado por una ventana grande que contiene estampadas las reglas de uso del sauna, y por el que además entran los tenues rayos del sol, ya que el jacuzzi está justo debajo de un tragaluz. Cuando se acerca la noche, el sauna poco a poco entra en la oscuridad, que no es completa por la luz de un foco exterior que se enciende cuando se acerca la noche. De este modo, entre las 5:30 pm y las 6:30 pm, cuando la luz del sol comienza a desaparecer, el ingreso de los usuarios al sauna es mayor y los actos sexuales públicos hacen su aparición. Por cuenta de la oscuridad, que no es total en ningún caso, el lugar deviene en un temporal cuarto oscuro, que además permite tales encuentros según otras variables, como la temperatura, la cantidad de personas en su interior (siempre variable), así como de la disposición personal de cada sujeto por participar activamente o no del sexo (en) público.

El segundo espacio notable es aquel donde se ubica el cuarto oscuro y las cabinas en el primero piso del sauna. Al igual que en el video, ambos se encuentran bastante cercanos, por lo que permite que quienes se encuentren en el primero y quieran mayor privacidad, accedan de forma rápida a ellas. Sucede también que algunos salen de esta zona y suben al segundo piso, donde se encuentran otras cabinas menos concurridas y cercanas a la recepción. Al igual que en el del video, este cuarto oscuro maneja diferentes grados de

Fernando Ramírez Arcos 
oscuridad, ya que una parte de él es contigua a un pasillo, del cual está separado por una ventana de acrílico. En el pasillo se encuentran un foco y un televisor en proyección continua de televisión por cable, cuyas luces entran y producen grados de luminosidad que, contrario a lo que se puede pensar, no impiden los encuentros sexuales. De todas maneras, es preciso indicar que el cuarto oscuro del sauna es mucho más pequeño, tiene sillas en cerámica que permite que los clientes se sienten y que el acrílico difumina las luces de tal manera que la visibilidad es reducida. En contraste, las cabinas contiguas son espacios poco frecuentados, con mayor luminosidad y tan amplias como las del video. Por último, es preciso anotar que justo entre ambos espacios, en el techo, se encuentra un parlante que profiere los mismos géneros musicales que en el video, a un volumen similar, por lo que es notoria su función reguladora de sonidos públicos sexuales.

Aunque en primera instancia son similares a los del video, lo cierto es que las cabinas y el cuarto oscuro del sauna son espacios de connotación sexual pública que difieren en intensidad $y$ frecuencia por la diversificación de los servicios del establecimiento, que permiten que sus clientes se dispersen y accedan a otros espacios para relajamiento y descanso. Por ejemplo, observé que algunos sujetos prefieren mantenerse a raya de estos espacios para buscar la tranquilidad que les ofrece los baños turcos o la piscina, sitios de menor tensión sexual, o asisten a ellos pero manteniendo una distancia bastante prudente. Los usos diferenciales que estos hombres hacen del lugar destacan la fluidez de los significados sexuales y de ocio que son puestos en circulación, lo que hace imposible prever las actuaciones de cada uno y los tipos de prácticas en que podrían incurrir. Por los servicios que ofrece, el sauna permite mayor variabilidad en las relaciones sociales que el video; diversidad que es puesta en juego alrededor del sexo, sin lugar a dudas, pero que imposibilita obviar otras actividades de ocio, como nadar, beber una cerveza en el área del bar o disfrutar del descanso que produce estar en los baños turcos o en el jacuzzi.

Por último, el tercer lugar de mi trabajo de campo lleva el sexo (en) público a otra dimensión. Se trata de un club de sexo que se ubica muy cerca al video que he descrito antes, en pleno corazón de Chapinero. Según Camilo Braz (2010), los clubes son herederos directos de los antiguos sitios leather de mediados del siglo XX que surgieron en Estados Unidos y Europa. Sus convenciones son reminiscencias del lenguaje propio de comunidades fetichistas y sadomasoquistas que por esa época se reunían para prácticas sexuales alternativas y para, en ocasiones, generar relacionamientos sociales y de amistad. El antropólogo brasilero destaca que tales convenciones son reapropiadas en los contextos geográficos locales y resignificadas por la diversidad de particularidades citadinas en torno al género y la sexualidad. Según su propia definición:

Los clubes de sexo masculinos (...) son una punta de un mercado pornográfico en torno a prácticas sexuales disidentes y experimentación erótica que incluye los clubes, tiendas de ropa y accesorios, sex shops, páginas de internet (y) productoras de filmes especializados en esas prácticas. E incluye también un circuito casi mundializado, visible en países del norte de Europa y los Estados Unidos, en España... y en Brasil (BRAZ, 2010, p. 99 - 100) ${ }^{9}$.

El club del sexo que investigué bien podría estar ubicado en São Paulo o Madrid, ciudades en que Braz realizó su investigación de doctorado. Las escenas y dinámicas que describe de su trabajo de campo, como ciertos elementos decorativos y convenciones pictóricas como aquellas de Tom of Finland, también aparecen en mi etnografía. Similitudes nada sorprendentes, por cuanto los dueños de este tipo de establecimientos pueden traer la idea de implementarlos de sus viajes al exterior y/o de conocidos que han estado fuera del país, adaptándolos pero manteniendo una línea común y definida de lo que es para ellos el sexo entre hombres fuera de los espacios de intimidad normativos o de cuartos oscuros y cabinas.

Este establecimiento en particular se ubica en el segundo piso de un pequeño edificio, cuya primera planta está ocupada por una discoteca convencional. Cuando se entra a él, se encuentra la recepción con el área de casilleros, donde se debe dejar toda la ropa (el nudismo es obligatorio), excepto los zapatos. Luego de dejar la ropa, el cliente puede acceder al bar y la pista central, donde acontecen los espectáculos principales de los fines de semana, que van del strip tease y actos sexuales de los clientes con los strippers, hasta fiestas temáticas alrededor del fisting, el uso de dildos y el pissing ${ }^{10}$. Unas cortinas dividen este escenario de la sala principal, donde a diferencia de los espacios del video y el sauna, el sexo es comunal y visible para todo el mundo. En vez de cabinas y cuartos oscuros, encontramos una extensa zona dividida por rejas y paredes de latón que discrimina espacios, pero a los que cualquier cliente puede acceder mientras los recorre. Esta zona crea la sensación de un ambiente de hard sex o de la escena BDSM, que resalta aún más

Fernando Ramírez Arcos 
por la presencia de cuadros de gran tamaño con imágenes de Tom of Finland, algunos pocos televisores con filmes pornográficos (muy poco asistidos), dispensadores de papel higiénico, y taburetes y camas de cuero de color negro o rojo, similares a las que se pueden encontrar en las cabinas del video y el sauna.

En un extremo de la sala principal se encuentra el dungeon, donde en ciertos días tienen lugar fiestas privadas alrededor del sadomasoquismo y el fetichismo. Esta área está decorada con muebles que incitan a la disciplina y a los juegos de dominación y sumisión. En mis últimas salidas de campo, en que el club cambió de división espacial interna (subdividió algunas áreas, expandió otras), el dungeon aumentó de tamaño, absorbiendo una antigua sala de televisión. Con esta expansión adquirió mayor centralidad, lo que indica que las intervenciones arquitectónicas son medidas de control que buscan dirigir las conductas de los sujetos, casi como si fueran ratones en un laberinto. Direccionamientos espaciales que también son notorios en los otros espacios privatizados de cruising visitados (por ejemplo, durante un corto tiempo de mi etnografía el video transformó una sala de televisión en un cuarto oscuro secundario), pero que en el caso del club de sexo son más frecuentes por cuanto las divisiones son fácilmente removibles, en contraste con aquellas hechas de cemento.

Como sucede en los otros lugares, las luces y la música también juegan aquí un papel importante. Mientras la recepción, el dungeon, el bar y los baños están suficientemente iluminados, la sala principal fluctúa entre diversos grados de oscuridad según la presencia predominante de luces de color rojo y azul. En algunos momentos de la noche las apagan completamente sin que la oscuridad total reine, porque el área del bar permanece iluminado y su luz penetra los intersticios dejados por las cortinas. Por tanto, la visibilidad sigue siendo un factor importante en el lugar, pero siempre está variando a juicio de los administradores, que las encienden y apagan según a su antojo. Por su lado, la música es similar en géneros, quizá con mayor predominancia de la electrónica, sólo que con un volumen mucho más alto. Además, los parlantes son más grandes y se encuentran ubicados en el piso, contiguos a las escenas sexuales.

Cabe notar que estas medidas de regulación hacen parte del manejo y gerenciamiento de las conductas de los cruisers en el espacio. En general, apelan a códigos sociales comunes y naturalizados de lo que entendemos como intimidad. El sexo tiende a aparecer en determinados sitios más que en otros, en especial si están poco iluminados. Aunque en el caso del club se fomentan los actos sexuales en cualquier sitio, lo cierto es que se regulan las conductas de los usuarios de maneras sutiles para que se relacionen entre ellos en ciertas áreas más que en otras. La forma más notoria de administración son los cambios constantes en su distribución espacial, como mencioné antes, aunque las luces y la música también colaboran en (de) sexualizar áreas y sujetos ${ }^{11}$. Los espacios producidos exponen una íntima relación entre los requerimientos de los dueños y empleados con los usos de los usuarios y los objetos, que indican que el sexo es orientación, guía y variable de orden espacial. Variable que nunca es posible controlar en su totalidad, ya que los espacios cambian continuamente, sea por deseo de quien está a cargo del establecimiento, sea por las interacciones propias de los cruisers. Límites de control que son permeables y dispuestos a reconfigurarse en todo momento.

\section{Cuestionamientos a la Geografía}

Quiero mencionar a continuación los cuatro principales cuestionamientos a la geografía derivados de mi trabajo de investigación.

\section{El sexo es una variable espacial}

He notado que algunos artículos y libros sobre la articulación entre sexualidad y geografía se quedan cortos en cuanto al sexo como práctica espacial. Por ejemplo, Don Mitchell (2000) cita el famoso trabajo Gay New York, de George Chauncey (1994), quien aborda lugares apropiados por hombres homosexuales de clase trabajadora a comienzos del siglo XX en la ciudad de Nueva York. El historiador estadounidense menciona baños, bares y lugares oscuros de los parques que se convierten en escenarios de encuentros anónimos. Mitchell trae a colación este trabajo para remarcar en el sexo (en) público como ejemplo de la apropiación de los hombres gay de los espacios citadinos, así como de la condición espacial del sexo, proceso dinámico y continuo en íntima relación con otras formaciones sociales. Señala, también, que tales apropiaciones estaban en constante peligro por la persecución de moralistas que buscaban sellarlos o eliminarlos. Mitchell plantea que la construcción de la sexualidad urbana - con el sexo como factor importante - es un proceso formado por relaciones antes que un proceso inmutable y estable, y que nunca está acabada, sea por la reterritorialización de nuevos escenarios, sea por la vigilancia constante de quienes implementan un orden determinado.

En conclusión, sostiene que el sexo es en sí mismo espacial, pero comete el error de subsumirlo a una mera descripción sin ahondar preguntas como: ¿por 
qué los hombres se encontraban justo ahí donde señala Chauncey en su libro? ¿Qué recorridos realizaban para encontrarse y luego dispersarse? ¿Cómo éstos se traducían en espacialidades? ¿Quiénes y por qué intervenían en los encuentros sexuales? ¿Qué efectos se derivaban de estas actividades? Planteamientos que pueden explicarse en Gay New York, pero ciertamente no en Cultural Geography. No basta con hacer una lista de los espacios que los hombres homosexuales frecuentaban (y frecuentan) para el cruising en Nueva York para decir que el sexo también es espacial; en este caso, la relación neta con el espacio requería particular mención. Para dar cuenta de ello, es necesario extenderse en el contexto en que sucede, con qué lógicas actúan los sujetos, quiénes lo practican, cómo aparece el sexo (en) público en el escenario de las calles y los parques, y cómo es confrontado por la policía, los medios de comunicación y las sociedades en general.

Además, es preciso evitar llamar gay a los hombres cuando es bien claro que tal identificación no tiene cabida en esa época en Estados Unidos; crítica que interpela a ambos autores. Es apresurado denominarlos con cualquier identidad, sea homosexual o $\mathrm{HSH}$ (hombres que tienen sexo con otros hombres), a los sujetos del cruising. Apresuramiento que hace parte del intento por entender lógicas espaciales según una matriz de inteligibilidad no adecuada y claramente heteronormativa. ¿Por qué no comprender los movimientos de estos hombres en el espacio público desde su propio punto de vista? Así, podríamos conocer cómo se encuentran con otros hombres, por qué realizan la elección de un lugar y no de otro, y cómo se escabullen para no ser encontrados por curiosos o la fuerza policial. Tacharlos con una identidad específica borra de un tajo significados del espacio que se explican desde la propia búsqueda del acto sexual.

Esta misma racionalidad debe ser aplicada incluso en lugares reconocidos por albergar relaciones sexuales entre hombres. En el sauna que visité en mi trabajo de campo, la identidad sexual de sus clientes no tiene la misma trascendencia que en otros contextos, como puede ser el caso de una manifestación pública en que se hace explícita la sigla LGBTI, como las marchas del orgullo gay, o en una salida de clóset ante la familia, entre otros ejemplos. Lo que interesa en el sauna, en su mayoría, es la búsqueda del acto sexual en sí, por lo que es preciso definir movilidades, espacialidades y rituales corporales de acercamiento y alejamiento. Si quienes lo practican se autoidentifican como bisexuales, gay, homosexuales y demás, es lo de menos en el ambiente de transitoriedad y anonimato que el lugar les brinda. No puedo decir lo mismo de la identidad de género, ya que 'ser hombre' es condición sine qua non de entrada. Por tanto, un trabajo investigativo sobre cruising, e incluso algunos otros de la geografía, requieren de teorías y metodologías que se aparten de la centralidad hegemónica de la heterosexualidad $\mathrm{y}$ la homonormatividad en la producción del conocimiento, que eviten el silenciamiento sobre el sexo y hablen de él como práctica ligada a la producción del espacio.

\section{Los lugares son fluctuantes en la producción de significados espaciales, sin que por ello pierdan su particularidad como lugar}

Gavin Brown (2008) examina los encuentros eróticos fortuitos y efímeros de algunos hombres en baños y zonas al aire libre de Londres. En su trabajo de campo reivindica sucesos de orden espacial que pasan desapercibidos (o al menos así parece) por personas heterosexuales que visitan los mismos lugares, que algunos hombres reapropian de ciertas maneras y en ciertas horas del día para tener sexo, al tiempo que interpela la cuestionada objetividad que el investigador debe tener en el campo. Al escribir sus impresiones de una forma directa y audaz, recrea el escenario que está contando como observador y como participante. Brown alega también ser cruiser, por lo que sus líneas muestran no sólo el panorama de lo observado, sino cómo ha sido él mismo afectado por la acción en que ha participado. Su cuerpo se percibe como lugar de cruising, un actor más junto a los espejos, los sanitarios, la cerámica, los árboles, la luz del sol o cualquier objeto animado e inanimado del lugar. De nuevo, fucking geography, pero ya no sólo para replantear la disciplina y sus métodos tradicionales, sino para hablar del sexo y de su cuerpo como acciones espaciales, y el espacio como máquina de subjetividades. Aquello que aún es vetado en la mayoría de círculos académicos, en esta etnografía se pone en relieve, al mostrar que el sexo en sí también contribuye a producir espacios, conocimientos y subjetividades que son follados.

Brown destaca que la geografía ha omitido considerar los actos sexuales como experiencias de importancia investigativa, de los cuales podría obtener buena información respecto a los espacios. Nombra el caso de los baños públicos, en el que unas personas asisten a ellos por necesidad física, mientras que otros acuden a encontrar parejas sexuales ocasionales. Mismo lugar, diferentes sentidos espaciales. Unos entran a orinar, defecar, lavarse las manos, arreglarse ante el espejo, cuando otros procuran un contacto sexual momentáneo. Los primeros se comportarán de determinada manera, generalmente con la cabeza baja,

Fernando Ramírez Arcos 
buscando el sanitario más próximo para terminar a la mayor brevedad posible el acto físico que los convoca; mientras tanto, los segundos serán más lentos en sus movimientos, caminarán de un lado para otro, repetirán algunas acciones como lavarse las manos y arreglarse la ropa, y estarán pendientes de quién entra y sale del baño, y quién les puede corresponder en su mirada. Este tipo de cruising adquiere el nombre de tearoom en el mundo anglosajón, que pone en juego una especie de economía del orgasmo, aquella que construye el baño (como otros lugares) como lugar de cruising según la disponibilidad y éxito de conseguir excitación

En el caso de los lugares de mi etnografía también aparecen objetivos diferentes de uso espacial, en que el sauna es el ejemplo más sobresaliente. Tuve la oportunidad de observar que mientras algunos clientes iban de un lado para otro mirando hombres, tanteando la posibilidad de un encuentro inmediato, otros hacían uso de los servicios de jacuzzi, sauna y piscina sin mayor ansiedad por relacionarse con otros. Se relajaban antes que todo. Incluso, era posible ver que algunos hombres ni siquiera estaban interesados en el sexo, sólo deseaban descansar y 'consumir con la mirada' cuerpos masculinos. Usos diferentes del espacio que no necesariamente van en contravía de lo que el sauna ha puesto a su disposición. Producción diversa de significados que construyen y delinean lo que es el sauna en sí.

Recordemos que un lugar no necesariamente es el mismo hoy que hace diez años, diez meses o diez minutos para cada uno de sus moradores, por lo que es preciso enfatizar en su carácter dinámico, en sus significados y en las relaciones sociales que lo construyen y configuran (MASSEY, 1994). Más bien, el lugar se revela como producto de la intersección de relaciones sociales y prácticas culturales que están en continuo movimiento, pero que en un instante preciso en el tiempo - espacio le da la particularidad que lo diferencia de los demás. Así, él también muda en sus sentidos e identidades, más aún si pertenece a una red de mercado erótico, como los lugares de mi investigación. En el caso del sauna, así sus clientes lo usen en mayoría para los encuentros sexuales, y en minoría para el descanso de sus obligaciones del día y la semana, no por eso deja de ser un sauna. Su particularidad está asegurada, su fluidez es constante pero limitada, y con el potencial de cambiar el espacio, así sea momentáneamente, en formas insospechadas (sexo cada vez menos privado, inutilización de ciertos espacios y sobreutilización de otros, cuerpos cada vez más esbeltos, entre otros posibles ejemplos). sexual pública entre hombres.

\section{El sexo confronta el ordenamiento espacial y social urbano establecido, en especial, de lo público y lo privado}

Hablemos por un momento del cruising en espacios al aire libre. En el Parque Nacional, lugar de ocio emblemático en la capital colombiana por su extensión, antigüedad y asiduidad de los bogotanos, es hogar de paso de reuniones familiares, actividades deportivas, transeúntes, y de hombres que buscan compañía sexual de otros hombres. Por esa situación, no son pocas las veces que la policía realiza rondas para atrapar incautos y llevarlos a sus comisarías por romper con la supuesta moral y la tranquilidad de la sociedad. A pesar de ello, es común que continúen en su búsqueda, a sabiendas de los peligros que los rodean, de los posibles robos, atracos y golpizas que puedan vivir, como ha ocurrido en algunas ocasiones. Este parque es un lugar fluctuante en sus usos y escenario de conflictos sexuales por el orden espacial que le ha sido asignado, el del entretenimiento público de los habitantes de la ciudad.

Enfrentamientos de otro orden por los espacios urbanos son parte de la etnografía de Brown en el tearoom londinense. Muestra cómo ciertos baños públicos fueron cerrados por temporadas, cómo algunos son reapropiados para el caso y cómo otros albergan mayor actividad que la usual. Los cruisers deben estar atentos al vigilante, al oficial de policía, a la presencia de intrusos, a posibles ataques violentos, a insultos, es decir, a encontrar el momento preciso que les brinde la mayor seguridad posible para sus encuentros, con un límite de riesgo aceptable. Seguridad que está en constante peligro, que es limitada porque aún si obtienen la oportunidad que buscan, el carácter público del lugar los obliga a maximizar las precauciones para evitar ser atrapados in fraganti. Pero al mismo tiempo, el riesgo de ser encontrados (o vistos y escuchados por otros cruisers) los excita y los convoca a transgredir fronteras naturalizadas de moralidad y socialización que, en espacios más privados, no sería posible. Como muy bien argumenta Brown, los "sitios de sexo público (...) crean oportunidades para los hombres de experimentar con (...) sus deseos homoeróticos en formas que podrían ser imposibles de alcanzar en otros espacios de sus vidas diarias"12 (BROWN, 2008, p. 928).

En mi opinión, el carácter de confrontación del cruising con el orden urbano de Bogotá desafía el poder heteronormativo que predica espacios higiénicos y homofóbicos. Lo que estos hombres realizan son transgresiones del sentido hegemónico del espacio, aquel que proclama que no deben 
realizarse ningún acto sexual en público, incluido nudismo genital. Nada de eso está permitido ni aquí, ni en muchas partes del mundo. Pero lo que las acciones anti-cruising provocan es la dispersión de la práctica a otros espacios no contemplados con anterioridad. Así, se obtiene el efecto es contrario: los lugares de encuentros sexuales al aire libre se multiplican; otros espacios no pensados con anterioridad para el sexo son reapropiados. De esa forma, la confrontación no sólo queda asegurada, sino que es desplazada a espacios previamente no contemplados, resignificando lo que es pensado como público y privado. Si los hombres son desterrados de uno de ellos, no por eso dejarán de buscar encuentros casuales. Por tanto, el conflicto territorial se resuelve en parte en contra de la heteronormatividad del paisaje urbano, ya que los hombres prueban más lugares públicos, observan cuáles les sirven y cuáles no, los comentan en redes virtuales y dejan algunas marcas físicas, como semen, empaques de condones y papel higiénico usado, como prueba de éxito de su búsqueda.

Con los sitios privatizados ocurre similar situación. Aunque en principio buscan evitar los riesgos antes descritos para que los hombres puedan con tranquilidad encontrar sexo fortuito, lo cierto es que su aparición en la escena pública homonormativa de Chapinero provoca cierta incomodidad en tiempos de lucha por el matrimonio entre parejas del mismo sexo. En una entrevista concedida al portal en internet Bogotá Rosa, el abogado Felipe Montoya, uno de los demandantes ante la Corte Constitucional por el reconocimiento de tal derecho como contrato civil con todas las garantías que goza una pareja heterosexual, responde afirmativamente a la pregunta de si se cambiarían imaginarios respecto a la comunidad LGBTI en Colombia si éste llegase a ser aprobado. Afirma que:

El 'sí' empezaría a mostrar las parejas del mismo sexo como parejas con capacidad de compromiso, que trascienden meramente la dimensión sexual. La gente habla de homosexualidad y de una vez se imagina cuartos oscuros, saunas, videos. Mostrará que nosotros somos tan buenos para conformar una familia y un hogar como lo es cualquiera (TRIVIÑO et al., s/f).

Por alguna perversa obsesión, muchos hombres gay están decididos a mostrar la mejor de sus caras (y sus cuerpos) ante la misma sociedad que se ha encargado de oprimirlos, humillarlos y violentarlos. Y digo perversa obsesión porque la frase de Montoya esconde al menos tres prácticas de fuerte regulación homosexual y espacial: primero, la naturalización del orgullo como emoción y sentimiento de los hombres gay, que deben sacar pecho por su homosexualidad; segundo, la visibilización a toda costa de 'lo gay', pero bajo los límites respetables de la moral y las buenas costumbres bogotanas; tercero, la discriminación hacia aquellos sujetos que hacen de los cuartos oscuros, los saunas y los videos su vida social y sexual; hacia quienes no quieren conformar familias $\mathrm{y}$ hogares heteronormativos y hacia quienes buscan relacionarse con otros hombres sin buscar compromisos serios de parejas monógamas y fieles, cuyo objetivo final sea el matrimonio civil. Además, mantiene una velada jerarquización de los espacios posibles de socializar y encontrar otros hombres. Un sauna o un video no sería el prototipo de espacio homosexual. En sí, el cruising y su presencia en los escenarios urbanos confrontan lo heteronormativo de la ciudad y lo homonormativo de su comunidad LGBTI.

\section{El sexo cuestiona políticas de legitimación y autoridad geográficas}

Fue precisamente la marginalidad geográfica del cruising, su identificación como geoperversión (BELL, 1995), lo que llevó a plantear mi trabajo de campo en los tres sitios mencionados. Cuando comencé a visitarlos, recordé que en algún momento de mi vida me enseñaron que son espacios a los que no se debe ir, que están en la periferia social gay, que ir no es una alternativa social, y que si en algún momento he asistido, hablar en público de ello puede acarrearme castigos sociales. Es decir, los videos, saunas y clubes de sexo bogotanos son espacios - otros marginalizados por el discurso corriente de la homosexualidad masculina. Quien los nombre como opción válida y les dé igual o mayor importancia a la de ir a la discoteca o bar de moda, recae sobre él una serie de epítetos de connotación negativa, como promiscuo, pervertido, enfermo, portador activo de enfermedades venéreas y/o VIH-SIDA, entre otros. Incluso, algunas de las explicaciones generales del por qué estos hombres asisten a estos lugares es por su 'pobreza', 'fealdad' o falto de habilidades para el flirteo. Cualquiera que sea el caso, el objetivo de estas denominaciones es la misma: injuriar al cruiser.

La misma intencionalidad performativa del insulto recae sobre quienes investigamos sobre temas de género y sexualidad en la academia. Braz (2010) critica los tabús y silencios de su disciplina, la antropología, respecto a la supuesta objetividad científica y distanciamiento etnográfico que todo 
investigador debería tener en campo. Cita a Leap y Lewin, quienes señalan en la introducción del libro Out in the Field (1996) las sospechas y desconfianza que recaen sobre los antropólogos y antropólogas que estudian tópicos de esta naturaleza, sea por su identidad sexual, sea por "la (im)posibilidad de objetividad y distanciamiento etnográficos en los llamados estudios 'gays y lésbicos"' (BRAZ, 2010, p. 40-41). Por eso, él llama a su trabajo una etnografía 'impropia', que problematiza la posición del investigador en campo (ante sí mismo y quienes lo rodean), en la academia y en la escritura. Es claro que esos mismos señalamientos tienen eco en la disciplina geográfica.

Ahora bien, lo impropio es, de hecho, mucho más complejo. Sólo dos puntos a tener en cuenta (entre varios más). Primero, el investigador debe enfrentar la desconfianza que genera analizar espacios catalogados como íntimos, que sólo deberían concernir a sus directos implicados. Sedgwick (1990) enfrenta esa idea al recordarnos algunos casos legales en Estados Unidos donde lo privado del sexo entre hombres es materia de orden público del estado. Señala cómo el clóset, como "estructura definida de la opresión gay" (SEDGWICK, 1990 , p. 71) ${ }^{13}$, es ambigua en lo que concierne a la intimidad de los directos implicados en actividades sexuales entre personas del mismo sexo, como bien atestiguan los demandados de sus ejemplos. En la práctica, el clóset es una estructura que disciplina, regula y dirige las vidas homosexuales; vidas que no necesitan identificarse como tales, ya que no importa si es verdad o no que una persona se identifique como tal, porque con la sola presunción basta. Como bastión de poder es siempre público, así la cama, la calle oscura o el cuarto oscuro brinden ficticias sensaciones de seguridad y libertad que los lugares de cruising privatizados se empeñan en acentuar. Ese silencio vedado sobre el sexo, que todos estamos obligados a respetar, es sólo una máscara que esconde y borra los efectos de un poder que discrimina y humilla sujetos, que ejerce su fuerza en los más recónditos y pequeños lugares espaciales (y corporales) que podamos imaginarnos, pero que pasan desapercibidos porque no hacen parte de lo que, por tradición, se piensa es público o geográfico.

Segundo punto: ¿Hablar en la academia de temas sexuales de orden heterosexual tendría la misma censura que los de índole gay? Seguro que no. La validez del conocimiento también depende, en ciertos contextos, de la identidad sexual. Por tanto, lo impropio no termina en la presunción de homosexualidad, ni en la desconfianza que pueda existir sobre el quehacer en el campo, sobre las posibles actividades sexuales con los sujetos de su etnografía. Lo impropio cuestiona la autoridad (científica, pero también moral) del investigador, de la validez de sus estudios, de su legitimidad para cuestionar su disciplina, de su provocación a la heterosexualidad como régimen político privilegiado de producción de conocimiento.

\section{Conclusiones}

Trabajar sobre sexo y sus relaciones con el espacio provoca, ante todo, repensar el papel mismo del investigador en campo. Mi cuerpo, que maneja varias identidades y subjetividades que me permitieron estar en esos lugares, de ser testigo de primera fila de performances grupales sexuales que sólo son posibles de observar si se cumplen estrictos controles (empezando por la disponibilidad de investigar un tema aún considerado tabú en varios espacios académicos de América Latina), debe mantenerse en la objetividad $\mathrm{y}$ en la legitimidad propia del saber académico, o de lo contrario, el análisis queda en el limbo. Esto es aún más cierto en la disciplina geográfica, que omite de forma aterradora que el sexo y la sexualidad sean características propias de la producción de los espacios. Y si son tenidos en cuenta, se les margina a los estudios de género, que de por sí deben mantenerse a raya porque son sólo 'estudios de mujeres'. Por tanto, queda por ver cuán eficaz puede ser la presencia del cuerpo del investigador en el texto académico geográfico y en el propio trabajo de campo, incluso en espacios donde el sexo no es el tema principal. Por ejemplo, ¿Qué sucedería si algunas investigadoras o investigadores tienen relaciones sentimentales o sexuales con quienes, se supone, deben mantener una distancia prudente en campo?

La fuerza de transgresión académica, tal cual he querido matizarla en este artículo con mi propia investigación, es un acto de resignificación propio de cualquier geoperversión. Lo impropio debe ser parte de la disciplina geográfica, ya que le permita expandir horizontes y desafiar territorios epistemológicos dados por hecho para dar cuenta de lógicas espaciales que, de otro modo, pasan desapercibidos por lecturas racistas, patriarcales, heteronormativas y homonormativas de los espacios. Por ejemplo, no es posible hablar del sexo (en) público desde categorías que retoman la sexualidad como un asunto dado o que sólo concierne a un grupo sexual minorizado, como si ella no delineara también la heterosexualidad. Se requieren de nuevas metodologías que se acerquen a estos espacios-otros que están presentes en el cotidiano del paisaje urbano. De ahí la pertinencia de críticas feministas y de lecturas transgresoras ${ }^{14}$ que ayuden a rehacer la disciplina geográfica, sus teorías y su forma de estar en el campo. Joder a la geografía

Fernando Ramírez Arcos 
implica cuestionar las políticas académicas de lo que es apropiado para investigar y de lo que es (i)legítimo como conocimiento para observar los múltiples y variados matices de nuestros entornos espaciales.

1 Debo aclarar que no necesariamente es así en toda relación de cruising. Algunas veces ocurre que se pasa del anonimato y la casualidad a encuentros más frecuentes y reconocidos entre los mismos practicantes en otros espacios, o incluso en el mismo lugar.

2 Por privatizado entiendo lugares públicos de acceso restringido que tienen sus puertas abiertas si se cumplen ciertas condiciones: identidad de género (hombre), rango de edad (mayores de 18 años), pago de entrada (lo que se conoce como cover), comportamiento apropiado y aspecto de vestuario 'aceptable' (por ejemplo, no se admiten hombres que sugieran vivir en las calles). Acceso que cae en discriminaciones factuales sobre quién puede o no hacer parte de la clientela del lugar, sin obviar que adentro también se mantienen prácticas de jerarquización. Además, uso privatizar como verbo para hacer hincapié en el papel dual del dinero como promotor y controlador del sexo (en) público. El dinero promueve que existan más negocios y diversidad de servicios, pero al tiempo se convierte en una variable de control de clase, en donde los sitios más costosos son 'mejores' porque a ellos asisten personas con alta capacidad adquisitiva $y$, supuestamente, blanco/mestizos, atractivos, con buen nivel intelectual, buenos modales y exitosos, lo que elevaría su valor sexual.

$3 \quad$ Traducción propia.

$4 \quad$ Es común pensar que son antónimos, que si un espacio no es público es porque es privado. Estos autores critican tal reduccionismo epistémico.

5 Utilizo gay con comillas cuando quiero resaltar el manto de duda que se cierne sobre una identidad sexual específica en sujetos, espacios o situaciones particulares. Cuando uso la denominación sin comillas, indica que no existe cuestionamiento alguno de la identidad sexual, al menos en términos de representación discursiva.

6 La localidad es una división políticoadministrativa que agrupa un determinado número de barrios. Chapinero es la localidad más popular en cuanto a lo LGBTI, pero cuando la nombro en el artículo me refiero en exclusiva a la zona central, que es donde se ubica la gran mayoría de establecimientos identificados como gay. En el imaginario social, este reducido espacio es conocido como Chapigay.

7 Código discriminado de la siguiente manera: los sujetos pueden entrar con ropa, excepto con pantalón los días martes y sábado; sin pantalón y sin ropa interior los días lunes y jueves, y totalmente desnudos, excepto los zapatos, los días miércoles, viernes y domingo, que además son los de mayor concurrencia.

$8 \quad$ Al inicio de mi trabajo de campo, ciertas cabinas tenían pequeños huecos que permitían observar lo que ocurría en el espacio vecino. Algunas personas usaban papel higiénico o goma de mascar para taparlos. Luego de unos meses, los administradores los sellaron definitivamente.

$9 \quad$ Traducción propia.

10 Los días jueves, viernes y sábado, especialmente, el administrador del lugar propone fiestas temáticas en el área del bar. A esa actividad le llama una escuela de enseñanza, cuyo objetivo es mostrar a los clientes prácticas sexuales alternativas, explicarles cómo pueden realizarlas y proponerles que las repliquen en otros espacios.

11 Entre otras formas de regulación y producción espacial, como el valor de la entrada y de los productos, la conducta y actitud del administrador y los empleados, el vestuario y la desnudez de los clientes, las relaciones que ellos establecen con su entorno, sus actividades sexuales públicas, el tipo de objetos presentes en el lugar y su ubicación estratégica, los colores y sus tonos, la decoración, las fiestas temáticas, el género de los filmes pornográficos en rotación, la disponibilidad de revistas gay, el consumo controlado de alcohol y la presencia de drogas.
12 Traducción propia.
13 Traducción propia.
14 Véase especialmente Bell et al. (1995), Binnie (1997), Brown (2000), Browne et al. (2007), Grosz (1995), Johnston et al. (2010), McDowell (1999), Oswin (2008), Ribeiro et al. (2011), Silva et al. (2011). 


\section{Referências}

BELL, David. 1995. (screw)ING GEOGRAPHY (censor's versión). Environment and Planning D: Society and Space, v. 13, n. 2, p. 127 - 131, 1995.

BELL, David. Fucking Geography, Again. En: BROWNE, Kath; LIM, Jason; BROWN, Gavin Brown (Eds.) Geographies of Sexualities: Theory, Practices and Politics. Hampshire: Ashgate Publishing Limited, 2007, p. $81-86$.

BELL, David; VALENTINE, Gill (Eds.). Mappig Desire: Geographies of Sexualities. Londres y Nueva York: Routledge, 1995.

BINNIE, Jon. Coming Out of Geography: towards a queer epistemology? Environment and Planning D: Society and Space, v. 15, n. 2, p. 223 - 237, 1997.

BROWN, Gavin. Ceramics, clothing and other bodies: affective geographies of homoerotic cruising encounters. Social \& Cultural Geography, v. 9, n. 8, p. $915-932,2008$.

BROWN, Michael. Closet Space: Geographies of metaphor from the body to the globe. Londres $y$ Nueva York: Routledge, 2000.

BROWNE, Kath; LIM, Jason; BROWN, Gavin (Eds.). Geographies of Sexualities: Theory, Practices and Politics. Hampshire: Ashgate, 2007.

CALIFIA, Pat. Public Sex: The Culture of Radical Sex. San Francisco: Cleis Press, 2000.

CHAUNCEY, George. Gay New York. Nueva York: BasicBooks, 1994.

DUNCAN, Nancy (Ed.). BodySpace: destabilizing geographies of gender and sexuality. Nueva York y Londres: Routledge, 1996.

GROSZ, Elizabeth. Space, Time, and Perversion. Nueva York y Londres: Routledge, 1995.

HOLLISTER. A Highway Rest Area as a Socially Reproducible Site. En: LEAP, William L. (Ed.) Public Sex / Gay Space. Nueva York: Columbia University Press, 1999, p. 55 - 70.

HUBBARD, Phil. Cities and sexualities. Nueva York: Routledge, 2012.
JOHNSTON, Linda; LONGHURST, Robyn. Space, Place, and Sex: Geographies of Sexualities. Lanham: Rowman \& Littlefield Publishers, Inc., 2010.

LEAP, William L. Introduction. En: LEAP, William L. (Ed.) Public Sex / Gay Space. Nueva York: Columbia University Press, 1999, p. 1-21.

LEWIN, Ellen; LEAP, William L. Introduction. En: LEWIN, Ellen; LEAP, William L. (Eds.) Out in the Field: Reflections of Lesbian and Gay Anthropologists. Champaign: University of Illinois Press, 1996, p. 1 - 28.

LONGHURST, Robyn. Pregnant bodies in public places. Bodies: Exploring fluid boundaries. Londres: Routledge, 2001, p. 33 - 65.

MASSEY, Doreen. Space, place, and gender. Minneapolis: University of Minnesota Press, 1994.

MCDOWELL, Linda. Gender, Identity and Place: Understanding Feminist Geographies. Minneapolis: University of Minnesota Press, 1999.

MITCHELL, Don. Cultural Geography: A Critical Introduction. Oxford: Blackwell Publishing, 2000.

OSWIN, Natalie. Critical geographies and the uses of sexuality: deconstructing queer space. Progress in Human Geography, v. 32, n. 1, p. 89 - 103, 2008.

RIBEIRO, Miguel Angelo; OLIVEIRA, Rafael da Silva (orgs.). Território, sexo e prazer: olhares sobre o fenômeno da prostituição na geografia brasileira. Rio de Janeiro: Gramma, 2011.

SEDGWICK, Eve Kosofsky. Epistemology of the Closet. Berkeley and Los Angeles: University of California Press, 1990.

SILVA, Joseli Maria; SILVA, Augusto Cesar Pinheiro da (Orgs.). Espaço, gênero e poder: conectando fronteiras. Ponta Grossa: Todapalavra editora, 2011.

TRIVIÑO, Sandy, MEZA, Manuel. Matrimonio igualitario. Entre el sí y el no, un debate jurídico pero de fondo humano, S/F. [Disponible en: http://www.bogotarosa.com/nuevo/es/elcatre/Demanda /entrevista 1.html.] <Consultado en junio 5 de 2012>.

Recebido em 27 de dezembro de 2012. Aceito em 13 de março de 2013. 